\title{
MODERNIDADE LÍQUIDA E INFÂNCIAS NA ERA DIGITAL
}

\author{
LIQUID MODERNITY AND CHILDHOODS IN THE DIGITAL AGE
}

LA MODERNIDAD LÍQUIDA Y LA INFANCIA EN LA ERA DIGITAL

\author{
Martha Kaschny Borges \\ Professora Doutora da Universidade do Estado de Santa Catarina (UDESC) \\ marthakaschny@hotmail.com \\ Silviane De Luca Avila \\ Mestre em Educação pela Universidade do Estado de Santa Catarina (UDESC) \\ silvianeavila@gmail.com
}

\begin{abstract}
RESUMO: O sociólogo humanista Zygmunt Bauman, em seus livros publicados em 2001, 2004, 2008, aponta que a sociedade hodierna está passando por transformações que afetam as condições humanas, caracterizando-se pelo seu aspecto líquido e fluido. O autor intitula a atual organização social de "modernidade líquida" na qual as relações econômicas e sociais estão se tornando cada vez mais instáveis e instantâneas. Frente a estas reflexões se questiona: quais infâncias se desenvolvem atualmente, uma vez que elas se distinguem das anteriores, particularmente, em razão de uma expressiva incorporação das Tecnologias Digitais de Informação e Comunicação nas práticas e brincadeiras infantis. Com o objetivo de contribuir para a compreensão da infância na contemporaneidade, ou seja, da cyber-infância, este artigo se propõe a dialogar com o sociólogo Bauman, especialmente a partir do conceito de modernidade líquida e, também, com o filósofo Michel Serres $(2011,2012)$ que anuncia a emergência de um "novo ser" denominado "Polegarzinha", o qual desenvolve competências cognitivas próprias.
\end{abstract}

PALAVRAS-CHAVE: Modernidade líquida. Infâncias. Era digital. Cyber-infância.

ABSTRACT: The humanist sociologist Zygmunt Bauman in his books published in 2001, 2004, 2008 points out that today's society is going through many transformations that affect the human condition, characterized by their aspect liquid and fluid. The author entitles the current society of "Liquid Modernity", where social and economic relations are becoming increasingly unstable and instantaneous. Front these reflections we question: which childhoods that develop today, they are different from previous ones, particularly due to a significant incorporation of Digital Technologies of Information and Communication in the children's practices and games. In order to contribute to the understanding of childhood in contemporary, or cyber-childhood, this article dialogues with the sociologist Bauman, especially from the concept of liquid modernity and with the philosopher Michel Serres $(2011,2012)$ that advertises the emergence of a "new being" called "Thumbelina", who are developing own cognitive competencies.

KEYWORDS: Liquid modernity. Childhoods. Digital age. Cyber-childhood.

RESUMEN: El sociólogo humanista Zygmunt Bauman en sus libros publicados en 2001, 2004, 2008 señala que la sociedad moderna está pasando por transformaciones que afectan las condiciones humanas, lo que la caracteriza por su aspecto líquido y fluido. El autor intitula la actual organización social de "modernidad líquida" en el que las relaciones económicas y sociales están tornándose cada vez más inestable y instantáneas. Frente a estas reflexiones se cuestiona: Cuáles infancias está actualmente en desarrollo, una vez que ellas son diferentes de las anteriores, particularmente, en razón de una significativa incorporación de las Tecnologías Digitales de Información y Comunicación en las prácticas y juegos infantiles. Con el objetivo de contribuir para la comprensión de la infancia en la contemporaneidad, o sea, de la cyber-infancia, este artículo se propone a dialogar con el sociólogo Bauman, especialmente, a partir del concepto de modernidad líquida, y también, con el filósofo Michel Serres $(2011,2012)$ que anuncia la aparición de un "nuevo ser" llamado "Polegarcita" en cual desarrolla competencias cognitivas propias.

PALABRAS CLAVE: Modernidad líquida. Infancia. Era digital. Cyber-infancia. 


\section{1 | INTRODUÇÃO}

Vivemos em uma sociedade em transformação, diversas mudanças no nosso modo de vida ocorrem diariamente em um ritmo cada vez mais frenético. Uma nova forma de organização social e econômica vem se estabelecendo, trazendo diferentes maneiras de nos relacionarmos com os outros e com o mundo a nossa volta. Essas mudanças também trazem incertezas, inseguranças e contradições complexas para a sociedade e para os sujeitos da contemporaneidade.

O sociólogo humanista Zygmunt Bauman intitula esta organização social de "modernidade líquida" (2001). Polonês, nascido em 1925 e radicado na Inglaterra desde 1971, o autor afirma que a sociedade atual está em transformação e que uma nova ordem está em desenvolvimento. A "modernidade sólida", como ele intitula a sociedade moderna dos séculos XVIII e XIX, perdeu a sua firmeza e, atualmente, vivemos em um estado de liquidez, em que as nossas relações sociais e econômicas vêm se tornando cada vez mais flexíveis e fluidas.

Bauman (2001) utiliza a expressão líquida para realizar uma analogia entre as características deste estado físico da matéria e as particularidades da sociedade contemporânea. Ele associa a instabilidade do estado líquido dos fluidos às inseguranças e complexidades das atuais relações sociais e econômicas. Afirma ainda que, ao contrário da modernidade sólida, que nos fornecia e prometia a estabilidade, a certeza e a durabilidade, a sociedade atual se transformou. Assim, a modernidade atual ou "líquida" se caracteriza pelas incertezas, pela instabilidade e pelo instantâneo, na qual tudo pode escoar de nossas mãos a qualquer momento.

\footnotetext{
O que todas essas características dos fluidos mostram, em linguagem simples, é que os líquidos, diferentemente dos sólidos, não mantém sua forma com facilidade. Os fluidos, por assim dizer, não fixam o espaço nem prendem o tempo. Enquanto os sólidos têm dimensões espaciais claras, mas neutralizam o impacto e, portanto, diminuem a significação do tempo (resistem efetivamente seu fluxo ou o tornam irrelevante), os fluidos não se atêm muito a qualquer forma e estão constantemente prontos (e propensos) a mudá-la; assim, para eles, o que conta é o tempo, mais do que o espaço que Ihes toca ocupar; o espaço que, afinal, preenchem apenas "por um momento". [...] Os fluidos se movem facilmente. Eles "fluem", "escorrem", "esvaem-se", "respingam", "transbordam", "vazam", "inundam", "borrifam", "pingam"; são "filtrados", "destilados"; diferentemente dos sólidos, não são facilmente contidos - contornam certos obstáculos, dissolvem outros e invadem ou inundam seu caminho. (BAUMAN, 2001, p. 8, grifo do autor).
}

Assim como os líquidos, as condições humanas atuais vêm se tornando mais fluidas, escorregadias e instantâneas, propensas a se desfazerem ou a se locomoverem diante de qualquer perturbação. Houve um "derretimento dos sólidos" (BAUMAN, 2001, p. 12). Estamos vivendo um momento em que tudo se torna mais maleável, no qual os objetivos individuais e momentâneos estão em ascensão em comparação aos interesses das instituições sólidas e fixas. Relacionamentos, laços sociais, afetividade, empregos, economia, segurança, liberdade e, inclusive, o amor tendem, com a modernidade líquida, a estarem sempre em fluxo como que "desenraizados".

Frente a estas condições humanas apresentadas por Bauman, nos questionamos: que infâncias estão se desenvolvendo na sociedade contemporânea? Em uma sociedade em que o indivíduo é o foco, em que o consumismo é uma válvula de escape e os limites entre tempo e espaço estão cada vez menores, que infâncias encontramos? Reconhecemos que a criança também faz parte desta modernidade líquida, é influenciada por ela e também influencia a constituição deste modo de vida.

Utilizamos o termo infância no plural porque compreendemos que vivenciamos diferentes realidades atualmente e que muitos são os tipos de infâncias e de crianças que devem ser reconhe cidas legitimamente. Como afirma Dornelles: 


\begin{abstract}
Existem infâncias mais pobres e mais ricas, infâncias do Terceiro Mundo e dos países mais ricos, infâncias da tecnologia e dos buracos e esgotos, infâncias superprotegidas, abandonadas, socorridas, atendidas, desamadas, amadas, armadas, etc. Contudo, a modernidade ocidental, ao universalizar e naturalizar apenas uma destas infâncias como dependente e necessitando de proteção, passou a deixar de lado a sua diversidade. Em função disso, se acaba esquecendo que as infâncias são múltiplas e inventadas como produtos sociais e históricos. Muitas das crianças que vivem suas infâncias hoje fazem parte de um mundo em que explodem informações. (DORNELLES, 2005, p. 72).
\end{abstract}

O objetivo deste artigo é dialogar com as discussões do autor Zygmunt Bauman, realizando uma interlocução entre o conceito de modernidade líquida e a emergência de infâncias contemporâneas, especialmente a cyber-infância. Para tal, também dialogamos com o filósofo Michel Serres $(2011,2012)$ que descreve a emergência de um "novo ser" em constituição, denominado Polegarzinha (ou la petite poucette).

Infâncias que se caracterizam pelo convívio constante com as Tecnologias Digitais de Informação e Comunicação (TDIC) as quais são parte do seu cotidiano, desde os primeiros minutos de vida. Ressaltamos que estamos debatendo as infâncias na era digital, as quais fazem parte do atual contexto urbano ocidental e se desenvolvem por meio de processos políticos, sociais e históricos dessa sociedade líquida e extremamente tecnológica, mesmo reconhecendo que outras infâncias convivem em nossa sociedade.

Infâncias que são compostas por crianças que, desde muito pequenas, acessam e interagem com a hipermídia e suas múltiplas linguagens (SANTAELLA, 2004; SERRES, 2012), que procuram assuntos na internet e encontram uma infinidade de caminhos para acessar esta informação, ao se relacionarem desta forma com as TDIC, desenvolvem competências e comportamentos bastante diferentes dos sujeitos adultos. Assim, podemos dizer que uma nova infância está se constituindo, intitulada por Dornelles (2005) de cyber-infância.

É nesse contexto que pretendemos refletir sobre as infâncias na/da era digital, a partir do conceito de modernidade líquida exposto por Zygmunt Bauman e de Polegarzinha, um novo ser mutante, proposto por Michel Serres. É nossa intenção compreender quem é esta criança frente às consequências do modo de vida da atualidade.

Destacamos que este artigo é um princípio de uma reflexão, não tendo a pretensão de fazer generalizações ou afirmações definitivas. A intenção é trazer subsídios que auxiliem a compreender melhor quem é a criança que cresce na era digital, à luz da sociologia e da filosofia dos dois autores referenciados.

\title{
2 | MODERNIDADE LÍQUIDA
}

No ano de 2001 o sociólogo Zygmunt Bauman lança o livro intitulado "Modernidade líquida". Nele, o autor nos apresenta e expõe as mudanças que a atual sociedade está vivendo, traz para a discussão as novas condições humanas, mudanças que afetam todos os aspectos da nossa vida cotidiana. Ele nos indica que uma outra forma de interação social está se desenvolvendo caracterizada por sua liquidez e fluidez.

Segundo o autor, estamos vivendo uma versão mais individualizada e privatizada da modernidade, na qual as escolhas individuais ganham maior destaque do que as escolhas das instituições ou coletivas e, consequentemente, as responsabilidades pelo sucesso ou pelo fracasso também se tornam individuais. $O$ indivíduo se tornou o foco, não porque este agora possui muitas escolhas ou caminhos, mas, sim, porque esta é a fatalidade do estado líquido em que nos encontramos: a constante dúvida por onde seguir. 
Tudo, por assim dizer, corre agora por conta do indivíduo. Cabe ao indivíduo descobrir o que é capaz de fazer, esticar essa capacidade ao máximo e escolher os fins a que essa capacidade poderia melhor servir - isto é, com a máxima satisfação concebível. (BAUMAN, 2001, p. 74).

Temos múltiplas possibilidades de carreira, de formação, de consumo, de relacionamentos. Sentimos que estamos livres para realizar escolhas e, assim, buscamos muitas satisfações (que na maioria das vezes são momentâneas). O autor nos mostra que a liberdade individual, sem considerar o coletivo e a sociedade como um todo, gera ainda mais incertezas e faz com que vivenciemos um estado de agonia constante (BAUMAN, 2001, p. 28).

Nesse estado de individualismo, a noção do que é público e do que é privado se altera drasticamente. O público se torna privado e as questões políticas com "p" maiúsculo, como coloca o autor, se reduzem consideravelmente. Ou seja, as fronteiras entre o público e o privado também estão mais maleáveis, estão se redefinindo, pois o que vem ganhando destaque na cena política são os problemas privados e não mais os de cunho coletivo. Assim, vemos a individualidade se estabelecendo, pois "[...] o modo como as pessoas individuais definem individualmente seus problemas individuais e os enfrentam com habilidades e recursos individuais é a única "questão pública" remanescente e o único objeto de "interesse público"” (BAUMAN, 2001, p. 85, grifo do autor).

Portanto, a principal busca na modernidade líquida, que se caracteriza pelo excessivo individualismo, é a busca pela segurança mais do que pela liberdade que anteriormente representava um dos objetivos da modernidade sólida. É uma busca por uma segurança na vida individual, baseada em escolhas individuais. Vivemos em uma sociedade que nos traz permanentes incertezas e instabilidades, então procuramos formas de nos segurarmos e nos apoiarmos. A diferença e o maior desafio na atualidade é que realizamos isso sozinhos e não mais coletivamente, como outrora.

Nessa busca por segurança e por satisfações, o consumismo se torna um dos principais caminhos, fenômeno destacado por Bauman no livro supracitado e em outro livro intitulado "Vida para consumo" (2008). Neste último, o autor afirma que somos uma sociedade do consumo, não apenas na compra de bens materiais e de serviços, mas também no consumo como estilo de vida, consumo de remédios, de produtos de beleza, de alimentação, de status social, inclusive, consumo de pessoas (no âmbito amoroso).

Consumir se tornou um dos comportamentos mais danoso da modernidade, pois agora está intrínseco à formação da identidade do ser humano. A possibilidade de desejar algo, de consumi-lo e, logo em seguida desejar outra opção, nos faz ainda mais incertos para realizarmos escolhas, uma vez que esta necessidade de consumir nunca será saciada. Afinal, o desejar é desejável.

A vida do consumidor, a vida de consumo, não se refere à aquisição e posse. Tampouco tem a ver com se livrar do que foi adquirido anteontem e exibido com orgulho no dia seguinte. Refere-se, em vez disso, principalmente e acima de tudo, a estar em movimento. (BAUMAN, 2008, p. 126).

E é por esta necessidade de constante movimento que o autor afirma que a noção de tempo também vem se alterando. A velocidade do tempo aumentou consideravelmente, o tempo precisa ser dinâmico e tão fluido quanto as necessidades atuais. A expressão "tempo é dinheiro" nunca foi tão verdadeira como na atualidade; há a necessidade de tornar o tempo algo instantâneo, que encurta distâncias. Nele, as negociações se realizam em tempo recorde, na velocidade da luz. Estamos presenciando o "tempo do software" (BAUMAN, 2001, p. 137, grifo do autor), temos a sensação de estar sempre correndo atrás dele e nunca o alcançar plenamente. $E$, consequentemente, atribuímos poder ao tempo: "A velocidade do movimento e o acesso a meios mais rápidos de mobilidade chegaram nos tempos modernos à posição de principal ferramenta do poder e da dominação" (BAUMAN, 2001, p. 16). 
Nessa busca constante pelo tempo, vivemos em urgência, por meio de instantes em que tudo é para ontem. Assim o espaço e sua estrutura sólida perde lugar para o tempo, que também é consumido.

O autor afirma ainda que a instantaneidade do tempo é mais dimensionada quando a relacionamos com o crescimento e a ampliação das TDIC. Com as tecnologias digitais, estamos sempre conectados, permanentemente em contato, não precisamos mais estar em um espaço definido para trabalharmos ou realizarmos transações econômicas, basta ter acesso a um dispositivo móvel com acesso à internet.

Esta possibilidade faz com que o capital econômico na modernidade líquida também se desapegue de espaços específicos. O capital pode viajar rápida e levemente apenas com uma bagagem de mão e um celular (BAUMAN, 2001, p. 70). O capital é móvel e não pretende mais ter longos e duradouros engajamentos, pelo contrário, ele procura relações que o permitam se locomover no momento apropriado, soltando-se das suas antigas condições e limitações, como, por exemplo, o espaço ou os trabalhadores.

A modernidade leve permitiu que um dos parceiros saísse da gaiola. A modernidade "sólida" era uma era de engajamento mútuo. A modernidade "fluida" é a época do desengajamento, da fuga fácil e da perseguição inútil. Na modernidade "líquida", mandam os mais escapadiços, os que são livres para se mover de modo imperceptível. (BAUMAN, 2001, p. 140 , grifo do autor).

Neste sentido, a condição do trabalho se altera radicalmente, uma vez que este também pode escapar das nossas mãos como um líquido. A estabilidade foi substituída pela flexibilidade e novamente vemos a incerteza e a angústia como um sentimento chave da sociedade atual. $O$ trabalho não fornece mais ao homem, como na modernidade sólida, uma segurança para toda a vida. O capital se torna desterritorializado e, assim, os trabalhadores precisam ser mais flexíveis às mudanças. Portanto, saber lidar e compreender as muitas mudanças é o desafio da modernidade líquida.

Nesta perspectiva, a flexibilidade, a fluidez e o desengajamento moldam a nossa identidade e provocam uma mudança nos valores, no trabalho, na formação, nos laços sociais e familiares, num espaço em que os objetos e as pessoas podem ser descartáveis e tudo deve ser aproveitado, saboreado e consumido aqui e agora. Todas essas mudanças que Zygmunt Bauman (2001, 2004,2008 ) aponta causam uma transformação profunda no modo como a sociedade hodierna opera e na forma como os indivíduos se relacionam. Portanto, estas mudanças também se apresentam na constituição das infâncias, afinal a criança é sujeito integrante da sociedade, na qual também é constituída e constituidora desta.

\section{3 | LIQUIDEZ E INFÂNCIAS NA ERA DIGITAL: modernidade, tecnologias e infâncias}

Zygmunt Bauman (2001, 2004, 2008) não se dedica especificamente a discutir infâncias e crianças, mas nos aponta alguns indícios para a reflexão aqui pretendida, principalmente quando admitimos que as infâncias estão intrinsecamente ligadas aos movimentos sociais e não podem ser separadas da atual condição humana. As crianças fazem parte desta realidade e também vivem no estado de liquidez apresentado pelo autor. O modo de vida infantil vem apresentando características líquidas, mesmo quando os sujeitos adultos ainda não admitem ou não a conside- rem como tal.

As infâncias não são sem tempo, elas também são subjetivadas pelas mudanças históricas e institucionais que modelam toda a sociedade (afinal, são construções histórico-sociais). Por isso é preciso admitir e considerar que as crianças não são meras expectadoras dos acontecimentos, 
ao contrário, elas participam e influenciam a formação da sociedade hodierna. Não estão aquém da realidade e se modificam tanto quanto os sujeitos adultos com as mutações da modernidade.

Como afirmado por Philippe Ariès, a ideia de infância e de criança é uma construção histórica e social que se iniciou no séc. XIII e foi se desenvolvendo principalmente durante o fim do séc. XVI e séc. XVII (ARIĖS, 2006). Assim, o sentimento de infância foi se transformando com as mudanças da sociedade. Na época medieval, este conceito não existia. Já no sec. XVI, nas camadas superiores da sociedade, surge a noção de infância caracterizada por sua ingenuidade, gentileza e graça. Nessa perspectiva, a criança precisa ser protegida e preservada (ARIĖS, 2006, p. 100). Muito desse sentimento permanece até os dias atuais.

\footnotetext{
Portanto, a invenção da infância implica na produção de saberes e "verdades" que têm a finalidade de descrever a criança, classificá-la, compará-la, diferenciá-la, hierarquizá-la, excluí-la, homogeneizá-la, segundo novas regras ou normas disciplinares. (DORNELLES, 2005, p. 19, grifo do autor).
}

Compreender que o conceito de infância é uma construção social e histórica que se modifica com o passar do tempo é perceber que, cada vez mais, as crianças participam desta construção e que todos os acontecimentos e mudanças da sociedade também chegam a elas, inclusive, o estado líquido que Bauman nos apresenta:

O fenômeno que todos esses conceitos tentam captar e articular é a experiência combinada da falta de garantias (de posição, títulos e sobrevivência), da incerteza (em relação à continuação e estabilidade futura) e de insegurança (do corpo, do eu e de suas extensões: posses, vizinhança, comunidade). (BAUMAN, 2001, p. 184).

As crianças convivem com a falta de garantias, as incertezas e as inseguranças da modernidade líquida. Esta também é a sua realidade e, desde muito cedo, elas lidam de diferentes formas com estas questões. Por mais que os sujeitos adultos tentem protegê-las e excluí-las desta situação, percebemos que este modo de vida já é intrínseco à identidade e às subjetividades de todos os envolvidos.

Isso não significa que a infância está desaparecendo, como propõe Neil Postman (1999). Acreditamos que novas formas de infâncias estão surgindo e se desenvolvendo com aspectos positivos e negativos. As crianças nascidas nos anos 2000 estão chegando às escolas e é preciso que reconheçamos que são sujeitos diferentes daqueles nascidos em décadas anteriores. Relembramos que estamos nos referindo às infâncias no contexto urbano ocidental, no qual as TDIC fazem parte do seu cotidiano, desde os primeiros momentos de sua vida, mesmo daquelas oriundas de classes menos privilegiadas.

Seria incipiente classificá-las em crianças da infância líquida. O fato é que elas possuem uma postura e uma identidade diferente dos sujeitos adultos, elas também convivem no estado de fluidez, assim como seus pais. Nesse contexto, elas constroem novas subjetividades e novas estratégias para lidar com a realidade, como afirmam os autores Green e Bigum (1995, p. 214, grifo do autor): "Mas o ponto que deve ser enfatizado aqui é que eles/as vivem essa incerteza de forma diferente, sempre envolvidos/as já, como estão, neste "jogo nervoso", no "jogo do futuro"'. Portanto, as Tecnologias Digitais de Informação e Comunicação têm feito parte da construção das subjetividades das crianças.

As crianças da era digital transitam e constroem a cibercultura. Esta é a realidade das crianças que, com apenas um clique, recebem uma avalanche de informações, sentados em frente a uma tela. Elas se informam, brincam e se comunicam por meio de hipermídias como YouTube, redes sociais e blogs. Assistem a vídeos ao mesmo tempo em que realizam a leitura de um texto e/ou de uma imagem. E se elas encontram algum link interessante? Ou se precisam descobrir o que 
significa tal palavra? Basta mais um clique e uma nova avalanche de informações e de possibilidades será iniciada.

Assim, as crianças da sociedade atual, ao mesmo tempo em que se constroem no seio da sociedade moderna e líquida, conforme a descrição de Bauman, também influenciam e direcionam esta sociedade. Mas afinal, quais as características das crianças da modernidade líquida? Quem são elas?

Para refletir sobre estas questões, apoiamo-nos particularmente na obra do filósofo francês Michel Serres, intitulada Polegarzinha (ou Petite Poucette, título original) publicada em 2012. Serres é um importante autor que contribui para a compreensão das infâncias na atualidade e mais especificamente sobre a cyber-infância, pois, segundo o autor, estamos hoje diante de uma geração mutante que nasce imersa no mundo rodeado por tecnologias. Para ele:

Eu o batizo como Polegarzinha por sua capacidade de enviar SMS com seu dedo polegar. É o estudante de hoje em dia, que vive um tsunami em um mundo que se modifica ao seu redor. Estamos vivendo em uma época de imensas mudanças, comparável àquela do fim do império romano ou da renascença. (SERRES, 2012, p. 17, tradução nossa).

E mais, o autor faz um apelo aos adultos em geral:

A geração mais jovem cresce em um mundo de pernas para o ar, com mudanças comparáveis às da Antiguidade. O planeta está mudando, eles também mudam, eles devem tudo reinventar. Vamos ser indulgentes com eles, eles são mutantes. (SERRES, 2012, p. 14, tradução nossa).

Portanto, a expansão das TDIC e o fácil acesso às hipermídias possibilitam múltiplas formas de interação com o mundo e com o conhecimento. E mais, as crianças são parte integrante desse fenômeno e, em decorrência dele, novas infâncias estão surgindo mediadas pelas TDIC, as quais apresentam características e maneiras de se relacionar diferentes das gerações anteriores e, em certa medida, semelhantes às características do estado líquido: incerteza, instabilidade, fluidez etc.

O surgimento destas infâncias se constitui em tema de estudo por parte de alguns autores que as denominam de muitas maneiras: cyber-infância (DORNELLES, 2005), infância midiática e geração eletrônica (BUCKINGHAM, 2007), geração-net por Don Tapscott, geração do computador por Seymour Papert (BUCKINGHAM, 2007), homo zapping (VEEN; VRAKKING, 2009), nativos digitais (PRENSKY, 2001), Polegarzinha (SERRES, 2011, 2012), dentre outras.

Agora são nas lan houses informatizadas que se produzem as infâncias globalizadas e este é o espaço da cyber-infância, ou seja, da infância on-line, da infância daqueles que estão conectados à esfera digital dos computadores, dos games, do mouse, do self-service, do controle-remoto, dos joysticks, do zapping. Esta é a infância da multimídia e das novas tecnologias. (DORNELLES, 2005, p. 80, grifo do autor).

Independente da nomenclatura utilizada, o fato é que as infâncias e a forma como as crianças interagem com o mundo ao seu redor está se modificando. São crianças que aprendem rapidamente como utilizar as tecnologias digitais e como encontrar a informação que desejam. Elas possuem, no mesmo dispositivo tecnológico, um computador ou um celular, formas de brincar, de aprender, de interagir com os outros por meio da rede, de construir seu conhecimento e de se relacionar, além da ubiquidade e da mobilidade de acesso à informação e à comunicação.

São crianças para as quais o mundo digital faz parte do seu cotidiano e que, muitas vezes, não sabem o que é não estarem conectadas. Estar off-line é quase impossível para elas, pois parte da 
sua socialização acontece no ciberespaço. Conversam em tempo real com parentes pelo Skype, correspondem-se por e-mail e redes sociais com amigos, postam fotos, criam e participam de blogs, fã-clubes e comunidades virtuais, criam diários, jogam, consomem livros, filmes, seriados e desenhos animados por meio da rede. E nesta dinâmica de clicar e buscar, não são apenas expectadores, elas participam ativamente da construção do seu conhecimento. "Desse modo, é fazendo uso destas possibilidades virtuais interativas que os cyber-infantes encontram novos modos de se sociabilizar e se produzir como sujeitos infantis de hoje" (DORNELLES, 2005, p. 86, grifo do autor).

Serres (2012) corrobora com a reflexão, afirmando:

O que sabemos com certeza é que as novas tecnologias não ativam as mesmas regiões do cérebro como os livros. Polegarzinha evolui, da mesma forma que evoluímos quando passamos do oral para o escrito. O que faziam nossos neurônios antes da invenção da escrita? As faculdades cognitivas e imaginativas não são estáveis nos seres humanos, e isto é muito interessante. Em qualquer caso, esta é minha resposta para os velhos rabugentos que a acusam de não ter memória nem uma mente analítica. Eles a julgam com as suas faculdades cognitivas e não admitem que o cérebro muda fisicamente. (SERRES, 2012, p. 21, tradução nossa).

As infâncias da era digital podem assim ser caracterizadas para além da familiaridade das crianças com as TDIC. Elas desenvolvem também grande interatividade com os outros no ciberespaço e grande agilidade para procurar e processar mais tarefas e informações ao mesmo tempo. Desde muito cedo, elas se acostumam a utilizar as tecnologias, inclusive, para muitas, o computador se constitui em mais um brinquedo disponível (GIRARDELLO, 2008). Assim, por meio de seus interesses, elas buscam jogos e informações sobre o seu livro ou filme favorito, conhecem outras crianças do seu país e do mundo pelas redes sociais e fan pages, formam novos laços afetivos (encontrando similaridades com crianças de outras culturas), diminuem distâncias e alteram a sua relação com o espaço e com o tempo.

Com relação às alterações destacadas por Bauman (2001), o autor nos mostra que a instantaneidade e a velocidade do tempo se tornaram muito importantes no estado líquido e que, de certa maneira, elas foram intensificadas pelo uso e pela expansão das TDIC. Nesse contexto, as infâncias também se desenvolvem no seio desta instantaneidade, a qual se constitui em um fenômeno integrante e formador de suas identidades e subjetividades, "moldando", assim, suas maneiras de pensar e de agir.

O sociólogo é bastante crítico, quando se refere ao uso da internet e sobre as relações online, indicando que estas são exemplos da liquidez dos laços sociais (BAUMAN, 2001, 2008). Para ele, o meio digital pode representar também um refúgio da vida real, uma vez que nos relacionamos com algumas pessoas apenas enquanto estamos conectados, no momento exato em que escoIhemos nos relacionar com elas. Para o autor, "Os internautas buscam, encontram e aproveitam os atalhos que levam diretamente do jogo da fantasia à aceitação social (embora, uma vez mais, apenas virtual) do faz-de-conta" (BAUMAN, 2008, p. 147).

Entretanto, quando refletimos sobre as crianças que convivem intensamente com as TDIC, percebemos que, muitas vezes, as relações online são, para elas, tão verdadeiras quanto as de "carne e osso". A afinidade dessas crianças com a rede e com o computador se estabeleceu de forma diferente daquela dos sujeitos adultos. As crianças da atualidade participam ativamente do mundo digital e se tornam coautoras de tudo aquilo que constroem no ciberespaço. Não são mais meras expectadoras da tela do computador, elas são ativas durante a sua navegação no ciberespaço, acessam diferentes sites, brincam, conversam, discutem, procuram, se informam, elaboram fansites e criam novos laços de amizades (AVILA, 2014). 
A relação das crianças com outras crianças via a rede se estabelece de diferentes formas, elas se tornam cúmplices na internet. Esforçam-se para aprender novas línguas e podem se comunicar com colegas do outro lado do mundo. Face a todas estas atitudes e características peculiares da cyber-infância, concordamos com Bauman (2001, 2004), quando este afirma que há uma fragilidade nos laços humanos da modernidade líquida. Nela, a insegurança causada pela condição humana atual estimula desejos conflitantes de, ao mesmo tempo, estreitar laços e mantê-los frouxos. Nesse sentido, a internet auxilia e fortalece esta contradição.

\begin{abstract}
Seria tolo e irresponsável culpar as engenhocas eletrônicas pelo lento, mas constante recuo da proximidade contínua, pessoal, direta, face a face, multifacetada e multiuso. E, no entanto, a proximidade virtual ostenta características que, no líquido mundo moderno, podem ser vistas, com boa razão, como vantajosas - mas que não podem ser facilmente obtidas sob as condições daquele outro tête-à-tête, não virtual. Não admira que a proximidade virtual tenha ganhado a preferência e seja praticada com maior zelo e espontaneidade do que qualquer forma de contiguidade. A solidão por trás da porta fechada de um quarto com um telefone celular à mão pode parecer uma condição menos arriscada e mais segura do que compartilhar o terreno doméstico comum. (BAUMAN, 2004, p. 84)..
\end{abstract}

É verdade que muitas crianças hoje, principalmente as de classes favorecidas, vivem mais tempo dentro de casa e/ou nas escolas do que na rua. Elas possuem muitos compromissos e aulas extracurriculares: balé, língua estrangeira, natação etc. Passam a maior parte do seu tempo confinadas, onde parecem estar mais seguras, levando uma vida mais privatizada, mais individualizada ou solitária, como aponta Bauman (2004).

Não podemos esperar que as crianças de hoje tenham o mesmo estilo de vida das crianças dos anos 70 ou 80, que brincavam de "amarelinha", de "polícia e ladrão" no meio da rua depois da escola. Vivemos outra realidade, a vida adulta não é a mesma e, consequentemente, a vida infantil também não. São novas formas de infâncias que apresentam suas próprias particularidades. Muitas brincadeiras infantis daquela época permanecem, mas hoje se encontram integradas aos jogos virtuais, não acontecem mais no meio da rua e, sim, dentro das escolas e de casa.

Assim, é preciso compreender que as mudanças nas infâncias podem ser positivas, criando diversas possibilidades e transformando a maneira como as crianças constroem conhecimentos e interagem com o mundo. Também podem ser negativas, deixando-as vulneráveis a diversas formas de violências e de abuso.

[...] o padrão das mudanças é complexo e ambíguo. As transformações contemporâneas na infância puxam ao mesmo tempo para diferentes direções. Assim, em alguns sentidos as crianças estão se tornando mais poderosas, enquanto outros estão ficando mais sujeitas ao controle adulto e institucional: em certas áreas, as fronteiras entre adultos e crianças estão se diluindo, enquanto em outras elas têm se tornado decididamente mais fortes. [...] Assim, a infância está sendo mais comercializada, mas ao mesmo tempo crescem as desigualdades de capital material e cultural que tornam difícil falarmos na "infância" em termos assim tão gerais. (BUCKINGHAM, 2007, p. 276, grifo do autor).

Ao mesmo tempo em que vivenciamos e observamos as crianças desenvolvendo novas habilidades, ao lidar com as TDIC e com as muitas situações do estado líquido, vemos essas crianças cada vez mais envolvidas com outros "perigos" da modernidade, como o consumo, que já se tornou um modo de vida, no sentido descrito por Bauman $(2001,2008)$. Não apenas consumo de bens materiais, mas também consumo como estilo de vida.

As crianças hoje em dia são tão consumidoras como qualquer adulto e vêm determinando novos rumos aos mercados econômicos e produtivos. Não são "meras vítimas passivas da manipulação 
comercial" (BUCKINGHAM, 2007), já que influenciam as compras da família, as estratégias de publicidade e movimentam um importante mercado de compra e de venda. Bauman (2008) afirma que:

Tão logo aprendem a ler, ou talvez bem antes, a "dependência das compras" se estabelece
nas crianças. Não há estratégias de treinamento distintas para meninos e meninas - o papel
de consumidor, diferentemente do de produtor, não tem especificidade de gênero. Numa socie-
dade de consumidores, todo mundo precisa ser, deve ser e tem que ser um consumidor por vo-
cação (ou seja, ver e tratar o consumo como vocação). (BAUMAN, 2008, p. 73, grifo do autor).

Ressaltamos novamente que é preciso entender que muitas são as infâncias, nem todas possuem o mesmo capital financeiro e de oportunidades, mas a dinâmica do consumo está presente em praticamente todas elas. Mesmo crianças com baixa renda fazem parte do mundo globalizado, consomem e têm contato com os mesmos desenhos animados, encontram formas de adquirir bonecas Barbie e roupas de marca (ainda que covers), também participam da cultura do consumo e são cidadãs consumidoras. Assim, as cyber-infâncias vêm ganhando poder e, mesmo com certas limitações, elas são um grande foco para o mercado.

Concluir que crianças de baixa renda não fazem parte desta realidade é um erro comum, principalmente quando falamos no contato destas com as TDIC, com maior ou menor intensidade. Elas frequentam lan houses, utilizam o computador na escola ou em casa de familiares e amigos, enfim, encontram formas de se inserir e de atuarem na cibercultura.

Assim, é preciso reconhecer que as infâncias da era digital ou a cyber-infância, como nomeia Dornelles (2005), possuem uma postura diferenciada em relação às TDIC e estão criando diferentes habilidades e estratégias mentais ao lidar com a hipermídia.

Essa geração de jovens e adolescentes, incluindo crianças em tenra idade, cria comunidades virtuais, desenvolvem softwares, fazem amigos virtuais, vivem novos relacionamentos, simulam novas experiências e identidades, encurtam as distâncias e os limites do tempo e do espaço e inventam novos sons, imagens e textos eletrônicos. Enfim, vivem a cibercultura. (FERREIRA; LIMA; PRETTO, 2005, p. 247).

Em muitos momentos, os computadores e as TDIC em geral são acusados de tornarem as pessoas antissociais, isolando-as do convívio social, por meio de um discurso que opõe os conceitos de realidade e de virtualidade. Esta também é uma dicotomia que não resiste a uma análise mais atenta, como a que realizou Lévy (1995), a qual é reforçada na obra de Serres:

\begin{abstract}
A este respeito, Polegarzinha não tem nada a inventar, o virtual é tão antigo quanto o mundo! Ulisses e Don Quixote eram virtuais. Madame Bovary fez amor virtualmente, e muito melhor, talvez, que a maioria de seus contemporâneos. As novas tecnologias podem ter acelerado o virtual, mas em nenhum caso, o criado. A verdadeira novidade é o acesso universal às pessoas por meio do Facebook, aos locais com o GPS e Google Earth, aos conhecimentos com a Wikipédia. Esteja ciente que o planeta, a humanidade, a cultura estão ao alcance de todos, que o progresso imenso! Vivemos em um novo espaço... A Nova Zelândia está aqui no meu iPhone! Ainda estou surpreso e encantado! (SERRES, 2011, p. 1, tradução nossa).
\end{abstract}

Assim, para esta nova geração, a cibercultura vem proporcionando outras possibilidades, novos espaços onde as crianças e os jovens se procuram e se agrupam em comunidades, buscam mais conhecimentos e soluções para suas dúvidas, com a ajuda de outros, informam-se sobre os acontecimentos do mundo, da sua cidade e dos seus direitos, enfim, uma geração que está fortalecendo uma cultura participativa. Para Jenkins (2009, p. 284), "Ao mesmo tempo, por meio 
da participação, as crianças estão traçando estratégias para lidar com a globalização [...]. Estão usando a Internet para se conectar a crianças do mundo todo e, desse modo, encontrando interesses comuns e forjando alianças políticas".

Isso não significa que podemos ter uma visão utópica sobre a cyber-infância ou sobre as TDIC e acreditar que estas podem trazer as soluções para todos os problemas, tornando as pessoas melhores e mais felizes. Em meio ao estado líquido em que nos encontramos e no qual as crianças estão crescendo, é importante compreendê-las e problematizar suas atitudes e competências. É importante, ainda, procurarmos entender as suas formas de pensar e de se organizarem, de como acessam a informação e de como interagem com os outros e com os acontecimentos da sociedade em geral. Buckingham (2007, p. 116) afirma que:

A infância, portanto, está certamente mudando. A vida das crianças é mais institucionalizada e privatizada, e menos estável e segura, do que era trinta anos atrás. As fronteiras entre crianças e adultos tornaram-se menos visíveis em algumas áreas, mas foram reforçadas e expandidas em outras. As crianças adquiriram poder, tanto político como econômico, mas também estão sujeitas a mais controle e vigilância por parte dos adultos.

Nesse sentido, a educação, os adultos e os professores possuem um papel fundamental: o de auxiliar as crianças no desenvolvimento da sua criticidade, auxiliá-las na busca de soluções em conjunto para os muitos desafios que se colocam à sua frente. Somos otimistas, ao pensar que esta geração, por ter nascido na modernidade líquida e com as condições humanas descritas por Bauman, munidas das competências cognitivas identificadas por Serres, podem se constituir em uma geração mais propensa a criar estratégias e habilidades para superar e lidar com o atual estilo de vida, principalmente quando a cultura participativa, por meio das diferentes mídias e TDIC, vem se fortalecendo e, desta forma, possibilitando às crianças a criação de estratégias de forma coletiva e colaborativa.

Bauman, em entrevista realizada pela professora Maria Lúcia Garcia Pallares-Burke (2004), ao ser perguntado "Qual seria sua mensagem para os jovens de hoje?", não se mostra tão esperançoso, mas afirma que os jovens podem encontrar soluções em si próprios:

Gostaria que tentassem, apesar de tudo, apesar de todas as tendências em contrário e de todas as pressões de fora, reter na consciência e na memória o valor da durabilidade, da constância, do compromisso. Eles não podem mais contar com a antiga geração, com a natureza permanente do mundo lá fora, com a durabilidade das instituições que tinham antes toda a probabilidade de sobreviver aos indivíduos. Isso não é mais possível e, na verdade, a vida humana individual, apesar de ser muito curta, abominavelmente curta, é a única entidade da sociedade de agora que tem sua longevidade aumentada. Sim, somente a vida humana individual vê crescer sua durabilidade, enquanto a vida de todas as outras entidades sociais que a rodeiam - instituições, ideias, movimentos políticos - é cada vez mais curta. Assim, o único sentido duradouro, o único significado que tem chance de deixar traços, rastos no mundo, de acrescentar algo ao mundo exterior, deve ser fruto de seu próprio esforço e trabalho. Os jovens podem contar unicamente com eles próprios e só haverá em suas vidas o sentido e a relevância que forem capazes de lhes dar. Sei que essa é uma tarefa muito difícil... mas é a única coisa que posso lhes dizer. (PALLARES-BURKE, 2004, p. 24, grifo do autor). 


\section{4 | CONSIDERAÇÕES FINAIS}

O líquido pode ser descrito como um estado físico que se adapta a diferentes formas e recipientes, sendo instável, ele escoa por entre os nossos dedos. Não é possível segurá-lo, o líquido flui, transborda, vaza, pinga e sai do controle com facilidade. Percebemos que muitas destas características poderiam também ser utilizadas para descrever as infâncias da era digital que, muitas vezes, não são facilmente compreendidas pelos adultos e, menos ainda, nas escolas.

As crianças da era digital também fazem parte da modernidade líquida e desta condição humana exposta por Zygmunt Bauman (2001, 2004, 2008). Elas não estão aquém desta realidade por serem crianças, pelo contrário, desde muito cedo suas vidas são afetadas pela liquidez da atual conjuntura social. Afinal elas não são simples expectadoras do estado líquido, elas o vivenciam e também o reproduzem. São constituídas e constituidoras desse modo de vida.

Nesse sentido, as crianças parecem preparadas para lidar e sobreviver neste estilo de vida, por sua rapidez, instantaneidade e, de certa forma, liquidez com que se relacionam com os outros e com o mundo ao seu redor. Suas competências cognitivas, afetivas, psicológicas e emocionais estão se adaptando para lidar com esta nova forma de organização social. Elas já vivem e convivem com a modernidade líquida desde os seus primeiros minutos de vida, ou seja, pensamos que, por elas fazerem parte desta realidade, têm mais possibilidade de buscar e criar diferentes soluções para enfrentar os desafios e as dificuldades de nossa era.

Entretanto, é preciso compreender que a cultura digital que pode ser utilizada a favor da constituição destes novos sujeitos, também pode desenvolver subjetividades sem a criticidade e as competências para lidar com a avalanche de informações diárias, as quais as crianças e futuros adultos têm acesso. Além disso, elas lidam constantemente com aspectos sociais individualistas e consumistas constituidores da modernidade líquida, o que pode trazer novos desafios para a sociedade e mesmo para o desenvolvimento das crianças. Como afirma Serres (2012, p. 28, tradução nossa): "Polegarzinha, devemos Ihe acordar muita atenção, uma vez que ela entra na era do indivíduo, sozinha no mundo. Para mim, a solidão é a fotografia do mundo moderno, ainda que superlotado."

Assim, esta geração pode encontrar soluções para os rumos negativos da globalização econômica, por exemplo, desenvolvendo uma globalização mais igualitária e justa. Para isso, é preciso que ela problematize a própria modernidade líquida, se conscientize da condição humana atual (e aqui destacamos a importância da educação). Vemos esta possibilidade principalmente por meio da cultura participativa que vem se desenvolvendo entre as crianças e os jovens no uso das tecnologias digitais.

E finalmente, é preciso entendermos que esta é uma nova organização social e que nela novos problemas e desafios surgirão, em consequência do modo de vida atual. Como estes sujeitos saberão lidar com diferentes situações e a permanência ou não do estado líquido, é impossível prever, mas é preciso considerarmos que esta nova forma de organização social que se desenvolve, também desenvolve novas infâncias. Independentemente das nomenclaturas atribuídas pelos autores (cyber-infância, polegarzinha, geração eletrônica, geração-net, homo zapping, entre outros), estas infâncias já estão presentes na nossa sociedade e, especialmente, em nossas escolas. Assim, refletir sobre elas e compreendê-las se constituem em atividade importante para nós, educadores e pesquisadores, a fim de que estas infâncias não "escoem" pelos nossos dedos. 


\section{Referências}

ARIĖS, P. História social da criança e da família. 2. ed. Rio de Janeiro: LTC, 2006.

AVILA, S. de L. Navegar no ciberespaço: as rotas de navegação de crianças em processo de alfabetização. 2014. 315 f. Dissertação (Mestrado em Educação)Universidade do Estado de Santa Catarina, Florianópolis, 2014.

BAUMAN, Z. Modernidade líquida. Rio de Janeiro: Zahar, 2001.

Amor líquido: sobre a fragilidade dos laços

humano. Rio de Janeiro: Zahar, 2004.

Vida para consumo: a transformação das

pessoas em mercadorias. Rio de Janeiro: Zahar, 2008.

BUCKINGHAM, D. Crescer na era das mídias eletrônicas. São Paulo: Loyola, 2007.

DORNELLES, L. V. Infâncias que nos escapam: da criança na rua à criança cyber. Petrópolis: Vozes, 2005.

FERREIRA, S. L.; LIMA, M. F. M.; PRETTO, N. L. Mídias digitais e educação: tudo ao mesmo tempo agora o tempo todo. BARBOSA FILHO, A.; CASTRO, C.; TOME, T. (Org.). Mídias digitais: convergência tecnológica e inclusão social. São Paulo: Paulinas, 2005, p. 225-255.

GIRARDELLO, G. Produção cultural infantil diante da tela: da TV à internet. In: FANTIN, M.; GIRARDELLO, G. (Org.). Liga, roda, clica: estudos em mídia, cultura e infância. Campinas: Papirus, 2008. p. 127-144.

GREEN, B.; BIGUM, C. Alienígenas na sala de aula. In: SILVA, T. T. (Org.). Alienígenas na sala de aula: uma introdução aos estudos culturais em educação. Petrópolis: Vozes, 1995. p. 208-240.
JENKINS, H. Cultura da convergência. 2. ed. São Paulo: Aleph, 2009.

LÉVY, P. As tecnologias da inteligência: o futuro do pensamento na era da informática. São Paulo: Editora 34, 1995.

PALLARES-BURKE, M. L. G. Entrevista com Zigmunt Bauman. Tempo social, São Paulo, v.16, n.1, p. 301325, jun. 2004. ISSN 0103-2070. Disponível em: <http:// dx.doi.org/10.1590/S0103-20702004000100015>. Acesso em: 15 jan. 2015.

POSTMAN, N. O desaparecimento da infância. Rio de Janeiro: Graphia, 1999.

PRENSKY, M. Nativos digitais, imigrantes digitais. NCB University Press, v. 9, n. 5, out. 2001. Disponível em: <http://pt.scribd.com/doc/55575941/Nativos-Digitais-Imigrantes-Digitais-Prensky>. Acesso em: $1 \mathrm{dez}$. 2014.

SANTAELLA, L. Navegar no ciberespaço: o perfil cognitivo do leitor imersivo. São Paulo: Paulus, 2004.

SERRES, M. Petite poucette. Paris: Le Pommier, 2012. Petite poucette, la génération mutante. Journal Libération, Paris, p. 1, 3 set. 2011. Disponível em: <http://www.liberation.fr/culture/2011/09/03/petite-poucette-la-generation-mutante_758710>. Acesso em: 15 jan. 2015

VEEN, W.; VRAKKING, B. Homo zappiens: educando na era digital. Porto Alegre: Artmed, 2009. 